\title{
The Marine Realms Information Bank Family of Digital Libraries: Access to Free Online Information for Coastal and Marine Science
}

\begin{abstract}
Searching the World Wide Web for reliable information about specific topics or locations can be frustrating: too many hits, too little relevance. A well-designed digital library, offering a carefully selected collection of online resources, is an attractive alternative to web search engines. The U.S. Geological Survey (USGS) provides three digital libraries for coastal and marine science to serve the needs of a diverse audiencescientists, public servants, educators, and the public.
\end{abstract}

\section{What is the MRIB family?}

USGS maintains three related digital libraries providing access to georeferenced (geographically indexed) information for coastal and marine science. The Marine Realms Information Bank (MRIB; http://mrib.usgs.govd) was developed in 2001 by the USGS Coastal and Marine Geology Program (CMGP) in partnership with the Woods Hole Oceanographic Institution (WHOI). MRIB encourages its users to discover online information about coastal and marine science by browsing a topical classification with 12 categories, including author, agency, project, location, feature type, and hot topics (fig. 1). In addition, MRIB utilizes maps for searching and retrieving georeferenced information. The USGS Monterey Bay Science Digital Library (http://mrib.usgs.gov/mbst) was released in 2004 as a prototype for regionally focused digital libraries based on MRIB software architecture. The newest member of the MRIB family is the topically focused Coastal Change Hazards Digital Library (http://mrib.usgs.gov/cch), released in 2006 (fig. 2).

\section{What is a distributed geolibrary?}

MRIB and its offshoots are distributed geolibraries as defined by the National Research Council (1999,

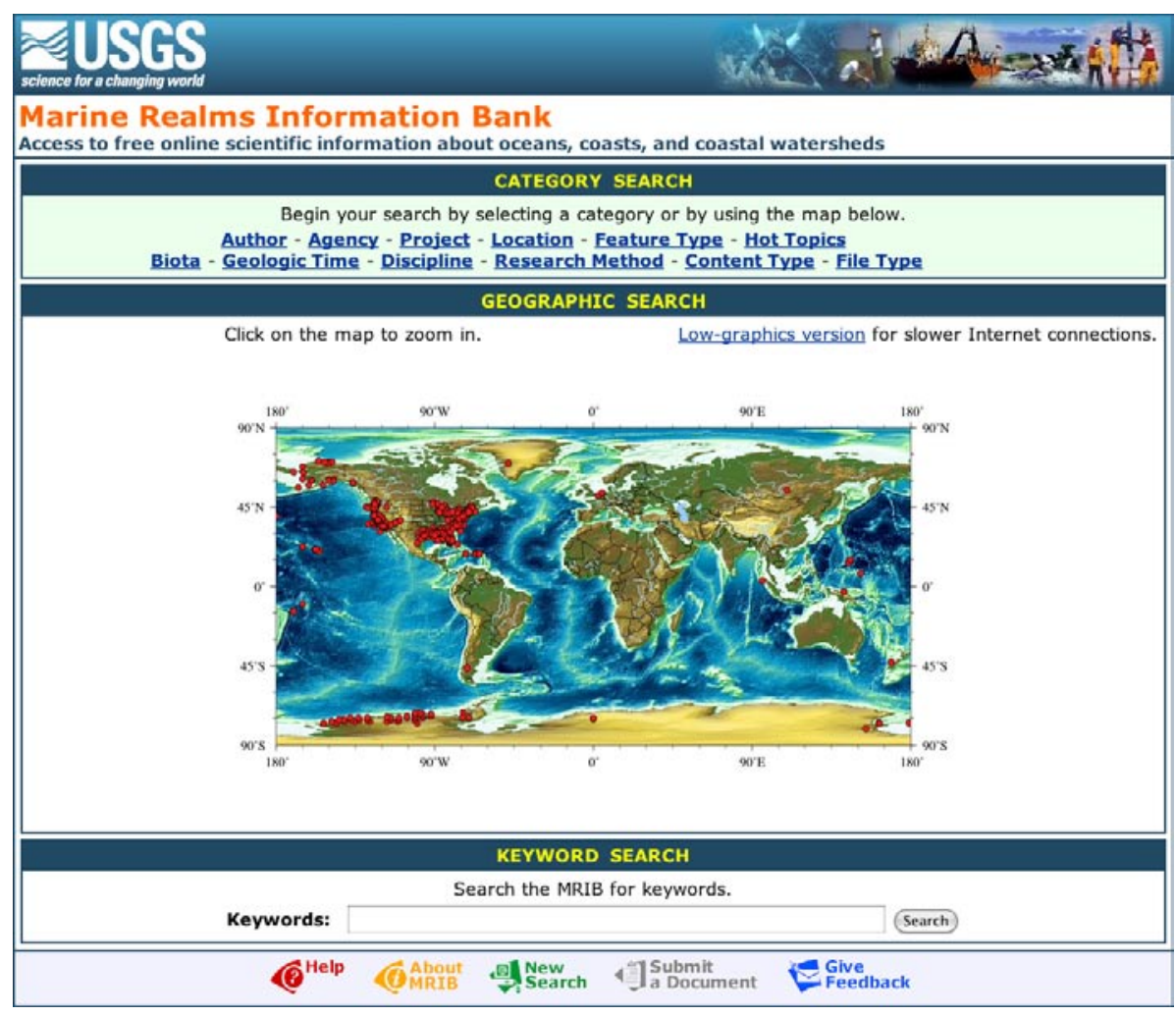

Figure 1. The Marine Realms Information Bank (MRIB), featuring three search options: by category, location, and keyword. The "Submit a Document" link at the bottom of the page connects the user to the Electronic Index Card Creation Utility.

p. 20-28). In the online environment, a distributed geolibrary allows patrons of the World Wide Web to find information about specific places or topics by searching centralized metadata records on the library server and then linking to the original online resources on servers distributed across the Internet.

\section{How do digital libraries differ from search engines?}

Web search engines such as Google offer full-text searching for billions of web pages, but the power and convenience of these search engines often come at a price: the user may be overwhelmed by thousands or millions of hits in a typical search, with little or no guidance for assessing the relevance and reliabil- ity of the search results. Despite recent refinements, these search engines still do not provide a coherent body of knowledge — only a list of links that might be relevant. A digital library, in contrast, helps its users cope with the enormous amount of unfiltered online information by offering a carefully selected, manageable collection of resources accessed through a knowledge organization system, or KOS (Hodge, 2000, p. 3-9). The KOS provides a common language and conceptual orientation for users lacking prior knowledge of the relevant keywords, leading authors, and benchmark papers in a given field.

MRIB uses a topical classification with 12 categories for guiding its users through the language and concepts of coastal and marine science. This KOS 
ZUSGS

\section{Coastal Change Hazards Digital Library}

Access to free online scientific information about natural hazards and human impacts in the coastal zone

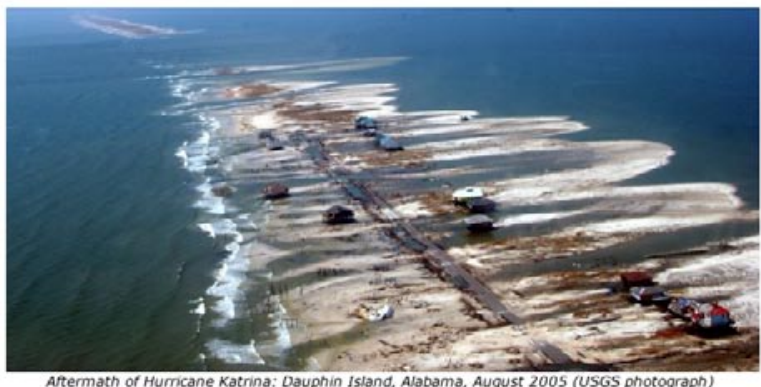

CATEGORY SEARCH

Begin your search by selecting a category.

Author - Agency - Project - Location - Feature Type - Topics - More Categories

GEOGRAPHIC SEARCH

Begin your search by selecting a region.

Atlantic Coast - Pacific Coast - Gulf Coast - Great Lakes - Alaska - Hawaii - More Regions

KEYWORD SEARCH

Begin your search by entering keywords.

Search
Advanced Options: Export Database

Keyword Search:

Search

Records per Page:

$10 \div$

Sort by Field:

Author :

Record Type:

All records

Go

Digital Library:

About

Submit a Document

Give Feedback

Help

Related Links:

Coastal and Marine

Digital Library (MRIB

Digital Library - USGS

Monterey Bay Science

Coastal and Marine

Geology Program

Figure 2. The Coastal Change Hazards Digital Library, a topically focused member of the Marine Realms Information Bank (MRIB) family, with a customized user interface providing access to about one-third of the MRIB database.

allows MRIB to accommodate users with differing backgrounds, interests, and vocabularies. Because many studies in the earth sciences concern particular geographic locations, MRIB also includes a gazetteer (dictionary of place names) and interactive map interface to emphasize geospatial associations between information resources and the physical world.

\section{How does MRIB work?}

In MRIB, scientific information is classified according to 12 independent criteria called facets. Each facet describes a different aspect of the information resource by using a controlled vocabulary of standardized terms to facilitate searching. The software for MRIB evolved from the WHOI 4DGeoBrowser, which uses electronic index cards (EICs) to store metadata profiles for its information content (Lerner and Maffei, 2001, p. 4-8, 17-18). Although creating these metadata profiles is a labor-intensive process, the MRIB user benefits by being able to submit precise search queries.

MRIB offers three types of searches: by category, by location, and by keyword. Users can select broad categories or narrow subcategories from the faceted classification, zoom in on a map, select named locations from the gazetteer, or search MRIB metadata for specific keywords or phrases. These operations can be applied repeatedly in any combination until the search is appropriately focused. At each stage of this process, MRIB displays the search results in browsable tables or interactive maps (at the user's discretion) and provides links to the original online resources.

\section{How can users contribute to MRIB?}

MRIB includes an EIC Creation Utility to guide the user through a stepby-step procedure for contributing new online resources to MRIB. The MRIB Team reviews all user contributions for suitability and accuracy before including them in the database.

\section{What is the importance of MRIB?}

As a public science agency, the USGS is responsible for delivering timely, reliable scientific data and information essential to meeting national needs and international obligations. The USGS CMGP fulfills this responsibility in part by creating digital libraries like MRIB for a wide range of users- scientists, public servants, advocacy groups, educators, and concerned citizens - who wish to learn about coastal and marine science, gather data for research, and make informed decisions.

\section{References Cited}

Hodge, Gail, 2000, Systems of knowledge organization for digital libraries-Beyond traditional authority files: Washington, D.C., Digital Library Federation, Council on Library and Information Resources, 37 p.; also accessed on March 9, 2007, and available online: http://www.clir.org/pubs abstract/pub91abst.htm

Lerner, Steven, and Maffei, Andrew, 2001, 4DGeoBrowser-A web-based data browser and server for accessing and analyzing multi-disciplinary data: Woods Hole, Mass., Woods Hole Oceanographic Institution, Technical Report WHOI-2001-13, 69 p.; also accessed on March 9, 2007, and available online: http://hdl.handle. net/1912/24

National Research Council, 1999, Distributed geolibraries-Spatial information resources, summary of a workshop: Washington, D.C., National Academy Press, 119 p.; also accessed on March 9, 2007, and available online: http://nap.edu/catalog/9460. htm

\section{By Frances L. Lightsom and} Alan O. Allwardt

For additional information contact:

Frances L. Lightsom

U.S. Geological Survey

Woods Hole Science Center

384 Woods Hole Road

Woods Hole, MA 02543

USA

flightsom@usgs.gov

or

Alan 0. Allwardt

U.S. Geological Survey

Pacific Science Center

400 Natural Bridges Drive

Santa Cruz, CA 95060

USA

aallwardt@usgs.gov

Any use of trade, product, or firm names in this publication is for descriptive purposes only and does not imply endorsement by the U.S. Government. 